\title{
Sex related difference of movement speed in the freshwater snail viviparus
} ater

\author{
Ribi, Georg ; Arter, Hubert
}

DOI: https://doi.org/10.1093/mollus/52.2.91

Posted at the Zurich Open Repository and Archive, University of Zurich ZORA URL: https://doi.org/10.5167/uzh-154796

Journal Article

Published Version

Originally published at:

Ribi, Georg; Arter, Hubert (1986). Sex related difference of movement speed in the freshwater snail viviparus ater. Journal of Molluscan Studies, 52(2):91-96.

DOI: https://doi.org/10.1093/mollus/52.2.91 


\title{
SEX RELATED DIFFERENCE OF MOVEMENT SPEED IN THE FRESHWATER SNAIL VIVIPARUS ATER
}

\author{
GEORG RIBI AND HUBERT ARTER \\ Zoologisches Museum der Universität Zürich, Winterthurerstr. 1908057 Zürich, Switzerland
}

(Received 1 July 1985)

\section{INTRODUCTION}

In gonochoristic species the fitness of males is highly linked to the number of matings, whereas in females, once enough sperm are obtained to ensure the fertilization of the eggs, additional matings may result in an increase in the variability but not the number of offspring (Las, 1980 ). Hence it is reasonable to assume that individual fitness is more closely related to the number of matings in males than in females.

The number of possible matings is correlated with the frequency of encounters between potential mates, and the encounter frequency is correlated with the rate of locomotion (Gerritsen \& Strickler, 1977). Locomotion, however, represents an investment of energy which can be measured in terms of the number of offspring produced, as shown for Drosophila subobscura Collin. (Inglesfield \& Begon, 1983) as well as for bugs (Braune, 1983) and water striders (Zera, 1984). In gastropods the energy cost of locomotion is high, partly because of mucus production (Denny, 1980). In fresh water snails, mucus produced during locomotion represents 13 to $32 \%$ of the energy absorbed through the gut wall (Calow, 1974).

Viviparus ater (Cristofori \& Jan) is a fresh water prosobranch snail which feeds on detritus and 'Aufwuchs'. It can also make use of particles suspended in the water column by filter feeding (Cook, 1949). The sexes are separate. The females are ovoviviparous and they give birth to offspring with a 6 to $11 \mathrm{~mm}$ shell width. While moving on the lake bed $V$. ater produces a band of mucus which may be considered an investment made into locomotion. Whether there are other costs of locomotion in $V$. ater, e.g. an increased mortality risk due to predation as suggested by Wells (1980), is not clear. If there is some non trivial cost for locomotion in $V$. ater, one would expect males to move at a higher rate than females. In this study we compare the distances travelled per day by males and females of $V$. ater in their natural habitat during the period when matings occur.

\section{METHODS}

Viviparus ater were collected near Wollishofen in Lake Zürich on 14 June 1982, by Scuba diving. In the laboratory 96 individuals (48 males and 48 females) were tagged individually by painting an area of the shell with liquid paper ('Tipp-Ex') and writing a number on it with a felt tip pen. They were divided into three groups of 16 males and 16 females each. The size distributions of the snails, ranging from 24 to $42 \mathrm{~mm}$ in shell height, were similar in the 3 groups. Each group was released at a different site in Lake Zürich on 15 June 1982. At each site a grid of 4 by $4 \mathrm{~m}$ had previously been set up between 2 and $3 \mathrm{~m}$ depth. On every $\mathrm{m}^{2}$ of the grid one male and one female were released. This corresponds to a population density which is within the range naturally occurring in Lake Zürich (Burla, 1972). During the following ten days the positions of the tagged snails were recorded daily.

Study sites 1 and 2 were at a distance of $50 \mathrm{~m}$ from each other near Erlenbach. Site 3 was at the opposite side of the lake near Rüschlikon (Fig. 1).

\section{RESULTS}

All the tagged snails moved during the period of observation. Of the 96 individuals initially released, 75 were still being observed on day 8 onwards. These were used in the analysis. On average, males covered almost twice the distance which females did. This holds for the length of the daily vectors (Table 1 ) as well as for the vectors between the point of release and the position of the last recording of each snail (Fig. 2). Multiple regressions showed that, of the 3 variables 'study site', 'sex' and 'size of snail', only sex had a significant effect on the length of both the daily vectors $(p<0.001)$ and the distance between the point of release and the position of the last recording $(p<0.001)$. The maximum distance travelled per day was $18.9 \mathrm{~m}$ for males and $9.8 \mathrm{~m}$ for females. 


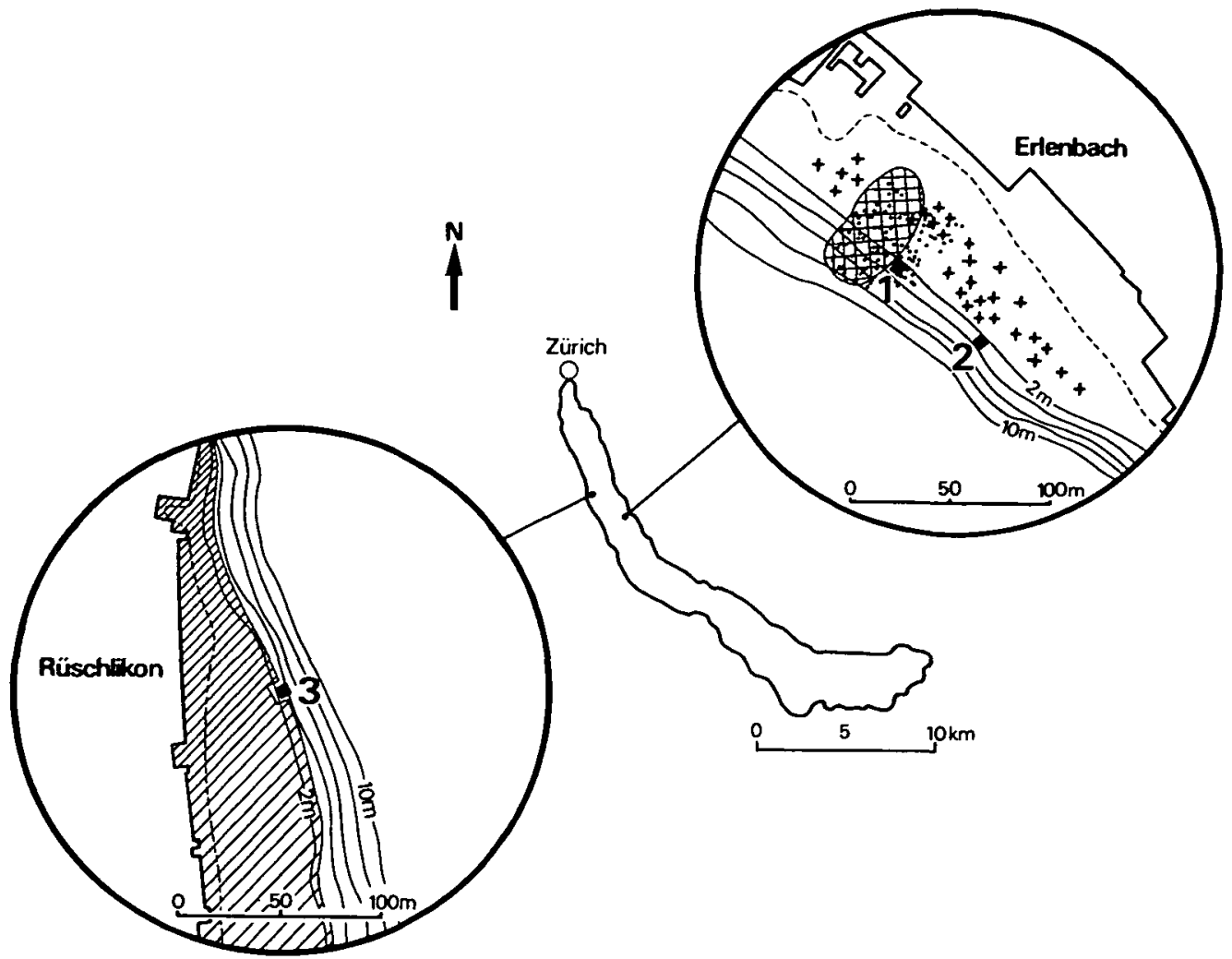

Fig. 1. Location of the study sites numbered 1 to 3 in Lake Zürich. The hatched area near site 1 represents a dense aggregation of green algae of the genus Cladophora. Scattered points indicate gravel; crosses Potamogeton perfoliatus. At site 3 the shaded area is a dense stand of $P$. pectinatus. Near the place of release an area of 10 by $10 \mathrm{~m}$ was cleared of vegetation at the beginning of the period of observations, in order to increase the detectability of the tagged snails.

The question whether the movement of the snails was directional or random cannot be answered unambiguously. If groups of snails of one sex which were released at one location are considered over a ten day period, it turns out that three out of six groups showed directional movement (Raleigh test, $\mathrm{p}<0.01$ ). These were the males released at sites 1 and 2 and the females released at site 3 (Fig 2). In contrast to this the daily vectors showed no directionality. The distribution of the changes of the direction between daily vectors was not significantly different from the hypothesis that changes in all directions were equally probable (V-test, Batschelet, 1981). Hence the directional movement over 10 days observed in some of the groups is a consequence of the lengths of vectors being different in different directions rather than of the circular distribution of the daily vectors.
The tagged snails tended to remain within a zone of between 2 and $6 \mathrm{~m}$ depth. The few individuals which migrated further towards the shore or into deeper water returned to their preferred depth within one or a few days.

There were striking differences between the movement patterns of individual snails. Some examples are given in Figure 3. A few individuals, all of which were males, showed directional movement covering large distances (Fig. 3a). A second group of snails frequently changed the direction resulting in a zigzag pattern (Fig. 3b). In a third group the movement was seemingly small to zero during several days (fig. 3c). The snail at the far right of Figure $3 \mathrm{c}$ remained half buried for four days. A small mound of faeces gradually accumulated next to it. It seems likely that the individual was filter feeding as described by Cook (1949). At other occasions we have 
Table 1. Mean distances travelled by Viviparus ater in Lake Zürich

\begin{tabular}{|c|c|c|c|c|c|c|c|c|}
\hline & $\begin{array}{l}\text { average distance } \\
\text { from point of } \\
\text { release after } \\
\text { ten days } \\
\text { (metres) }\end{array}$ & $\begin{array}{l}\text { standard } \\
\text { error } \\
\text { of mean }\end{array}$ & range & $\mathbf{n}$ & $\begin{array}{c}\text { average distance } \\
\text { travelled per } \\
\text { day } \\
\text { (metres) }\end{array}$ & $\begin{array}{l}\text { standard } \\
\text { error } \\
\text { of mean }\end{array}$ & range & $\mathbf{n}$ \\
\hline $\begin{array}{l}\text { males } \\
\text { females }\end{array}$ & $\begin{array}{l}9.4 \\
4.8\end{array}$ & $\begin{array}{l}1.64 \\
0.54\end{array}$ & $\begin{array}{l}0.7-42.0 \\
0.6-14.3\end{array}$ & $\begin{array}{l}42 \\
37\end{array}$ & $\begin{array}{l}2.5 \\
1.4\end{array}$ & $\begin{array}{l}0.36 \\
0.21\end{array}$ & $\begin{array}{c}0-18.8 \\
0-9.8\end{array}$ & $\begin{array}{l}263 \\
206\end{array}$ \\
\hline
\end{tabular}

observed individuals of $V$. ater with mounds of faeces near them which were almost the size of the animals themselves. Staying in one place and filter feeding may thus be a common behaviour in $V$. ater.

During the observational period snails were often seen in pairs. In all, 28 tagged individuals were involved which represent $4.2 \%$ of the total of the daily recordings of tagged snails made during the study. The 8 pairs observed in which both partners were tagged consisted of one male and one female each.

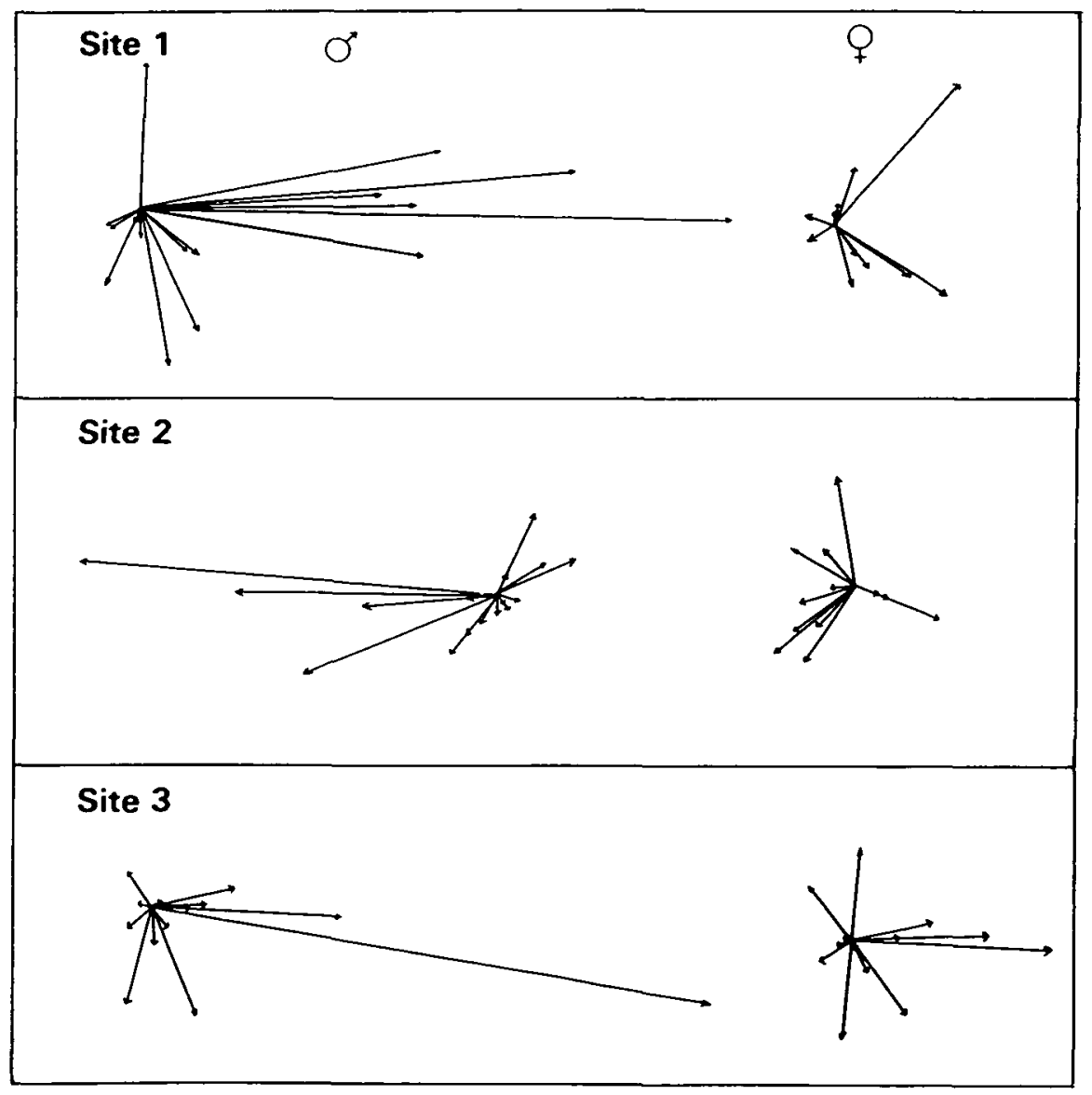

Fig. 2. Vectors between the point of release and the position of the last recording of Viviparus ater which had been observed for periods of between 8 and 10 days. The shore is at top. 


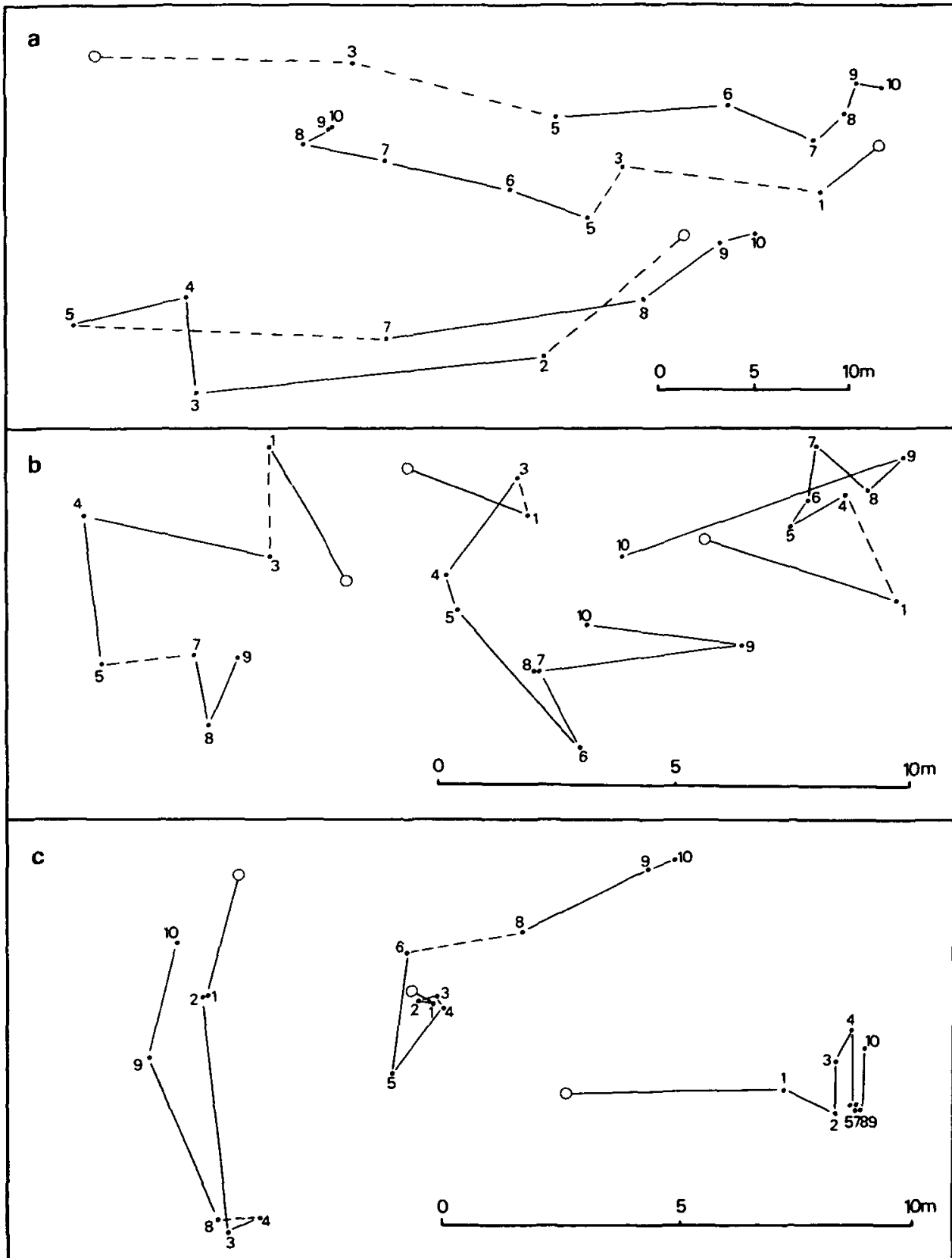

Fig. 3. Typical examples of the 3 types of movement observed in Viviparus ater, shown by the daily positions of different individuals. a) Individuals which maintained their heading for several days and which covered relatively large distances; b) individuals which frequently changed direction; $c$ ) individuals which were found at almost the same place for several days. Numbers indicate the day of observation after release; solid lines indicate daily vectors; dashed lines connect recordings separated by periods of 2 or more days. The shore is at top. 


\section{DISCUSSION}

In the recent literature animal movement patterns have been described and interpreted mostly with regard to foraging (Pyke 1984) and dispersal (Okubo, 1980). Other aspects of locomotion like predator avoidance (Sih, 1982) or mate finding (Silverman \& Bell, 1979) have less frequently been considered. The finding of the present study, that males of the prosobranch snail Viviparus ater covered greater distances than females, indicates that the movement pattern of this species cannot be adequately explained by foraging requirements nor by the need for active dispersal. However, the idea that the sexes have adopted different strategies in that males make a greater commitment to locomotion than females, needs further testing. It has to be demonstrated that locomotion is indeed associated with some non trivial cost in $V$. ater. Gastropod movement has been shown to be energetically more expensive, on average, than that of running invertebrates or vertebrates (Houlihan \& Innes, 1982). However, in Viviparus contectoides Binney the increase in oxygen consumption associated with increasing activity was not significant in males; in females it rose by approximately $60 \%$ from minimum to maximum activity (Fitch, 1975).

It is possible that snails are transported by water birds. Coots (Fulica atra L.) are known to feed on the mussel Dreissena polymorpha Pall. and may displace Viviparus to which mussels are attached. However, there are reasons to assume that this did not occur during the present study. First, coots were rare at the study sites during the period of observation. Second, attached mussels had been removed prior to tagging of the snails. Third, the daily positions of some of the snails indicate that they maintained the direction and the speed for several days (Fig. 3a). Such a pattern is unlikely to arise from transport by coots.

The distances covered by $V$. ater recorded during the present study are high as compared to values known from other gastropod species (Hamilton, 1978; Chelazzi, Focardi \& Deneubourg, 1983; Baur, 1984). Values similar to those of $V$. ater have been reported for the genus Busycon (Neogastropoda, Melongenidae) which covered an average distance of $18 \mathrm{~m}$ per day (Magelhaes, 1948), and for the slug Limax grossui Lupu which, in a laboratory experiment, moved at a rate of approximately $2 \mathrm{~m}$ in 30 minutes (Cook, 1977). The relatively large distances covered by $V$. ater will result in a higher rate of active diffusion as compared to other gastropod species. Since $V$. ater does not usually hold on to moving objects and because the offspring are relatively large when they are born, passive dispersal is probably rare. Therefore, crawling may be an important means of dispersal in $V$. ater.

The distribution of the changes of direction between daily vectors is consistent with the assumption of 'random walk'. In case of random movement the encounter rate between individuals increases as they move faster. However, an increase in the area of detection usually has an even stronger effect on the encounter rate (Gerritsen \& Strickler, 1977). Some species of snails increase the area of detection by conspecifics by producing a mucus track. The finding of a mate along a mucus track would be most efficient if the track would reveal information on the species, the sex and the direction of the individual producing the track. All three distinctions have been observed to be made by gastropods, although in different species. Nassarius vibex Say can discriminate mucus tracks of conspecifics from those made by individuals belonging to different species (Trott \& Dimock, 1978); Littorina planaxis Philippi follows the tracks made by individuals of the opposite sex more frequently than those of the own sex (Peters, 1964); Ilyanassa obsoleta Say follows the tracks of conspecifics in the direction in which they were laid (Trott \& Dimock, 1978), and Onchidium verruculatum Cuvier, an intertidal gastropod showing homing behaviour, can discriminate between outward and homeward trails made during feeding excursions (McFarlaine, 1981). In the present study we often observed $V$. ater at the head of clearly visible mucus tracks of up to $2 \mathrm{~m}$ in length. In some cases one or more individuals were seen to follow the mucus track at some distance behind the individual which had produced it. It is possible that mucus tracks play a role in mate finding in $V$. ater.

\section{SUMMARY}

1. At each of 3 sites in Lake Zürich a group of individually tagged Viviparus ater were released. Each group consisted of 16 males and 16 females. The position of the snails was recorded daily for 10 days.

2. The average distance covered per day was $2.5 \mathrm{~m}$ for males and $1.4 \mathrm{~m}$ for females. The maximum daily distance was $18.9 \mathrm{~m}$ for males and $9.8 \mathrm{~m}$ for females.

3. Some snails were observed at the same position for 2 to 4 days. Nearby mounds of faeces indicated that they were filter feeding. 
4. The males in two of the groups and the females in one group showed directional movement. The directionality resulted from the length of the daily displacements being different in different directions. The daily changes of direction were randomly distributed in both sexes in all the groups.

\section{ACKNOWLEDGMENTS}

We thank H. Burla, J.C. Camilleri and N.J. Evans for discussions and comments on the manuscript; P. Brauchli for drawing the figures.

\section{REFERENCES}

BATSChELET, E. 1981. Circular statistics in biology.(Mathematics in Biology). Academic Press, London.

BAUR, B. 1984. Dispersion, Bestandesdichte und Diffusion bei Arianta arbustorum (L.) (Mollusca, Pulmonata). Dissertation Universität Zürich, 1984.

BRAUNE, H.J. 1983. The influence of environmental factors on wing polymorphism in females of Leptopterna dolobrata (Heteroptera, Miridae). Oecologia, 60, 340-347.

BURLA, H. 1972. Die Abundanz von Anodonta, Unio pictorum, Viviparus ater, Lymnaea auricularia und Lymnaea ovata im Zürichsee, in Abhängigkeit von der Wassertiefe und zu verschiedene Jahreszeiten. Vierteljahrsschrift der Naturforschenden Gesellschaft in Zürich, 117, 129-151.

CaLOW, P. 1974. Some observations on locomotory strategies and their metabolic effects in two species of freshwater gastropods, Ancylus fluviatilis Müll. and Planorbis contortus Linn. Oecologia, 16, 149 161.

Chelazzi, G., Focardi, S. \& Deneubourg, J.L. 1983. A comparative study on the movement patterns of two sympatric tropical chitons (Mollusca: Polyplacophora). Marine Biology, 74, 115-125.

CoOK, A 1977. Mucus trail following by the slug Limax grossui Lupu. Animal Behaviour, 25, 774781.

Cook, P.M. 1949. A ciliary feeding mechanism in Viviparus viviparus (L.). Proceedings of the Malacological Society of London, 27, 265-271.

DENNY, M. 1980. Locomotion: the cost of gastropod crawling. Science, 208, 1288-1290.

FITCH, D.D. 1975. Oxygen consumption in the prosobranch snail Viviparus contectoides (Mollusca: Gastropoda)-1. Effects of weight and activity. Comparative Biochemistry and Physiology, 51a, 815-820.
GERRITSEN, J. \& STRICKLER, R. 1977. Encounter probabilities and community structure in zooplankton: a mathematical model. Journal of the Fisheries Research Board of Canada, 34, 73-82.

Hamilton, P.V. 1978. Intertidal distribution and long-term movements of Littorina irrorata (MolJusca: Gastropoda). Marine Biology, 46, 49-58.

Houlihan, D.F. \& INNES, A.J. 1982. Oxygen consumption, crawling speeds, and cost of transport in four Mediterranean intertidal gastropods. Journal of Comparative Physiology, 147, 113-121.

INGLESFIELD, C. \& BEGON, M. 1983. The ontogeny and cost of migration in Drosophila subobscura Collin. Biological Journal of the Linnean Society, 19, 9-15.

LAS, A. 1980. Male courtship persistence in the greenhouse whitefly Trialeurodes vaporariorum (Homoptera, Aleyrodidae). Behaviour, 72, 106-126.

MCFARLAINE, I.D. 1981. Trail following in the intertidal homing gastropod Onchidium verruculatum (Cuv.) The outward and homeward trails have a different information content. Journal of experimental marine Biology and Ecology, 51, 207-218.

MagelHaes, H. 1948. An ecological study of snails of the genus Busycon at Beaufort, North Carolina. Ecological Monographs, 18, 377-409.

OKUBo, A. 1980. Diffusion and ecological problems: mathematical models. Biomathematics, Vol. 10 Springer, Berlin, Heidelberg, New York.

PETERS, R.S. 1964. Function of the Cephalic Tentacles in Littorina planaxis (Gastropoda: Prosobranchia). Veliger, 7, 143-148.

PYKE, G.H. 1984. Optimal foraging theory: a critical review. Annual Review of Ecology and Systematics, 15, 523-575.

SiH, A. 1982. Foraging strategies and the avoidance of predation by an aquatic insect, Notonecta hoffmanni. Ecology, 63, 786-796.

SILVERMAN, J.M. \& BELI, W.J. 1979. The role of vertical and horizontal object orientation in mate finding and predator avoidance by the American Cockroach Periplaneta americana. Animal Behaviour, 27, 652-657.

TROTT, T.J. \& DiMOCK, R.V., jr. 1978. Intraspecific trail following by the mud snail Ilyanassa obsoleta. Marine Behavior and Physiology, 5, 91-101.

WELLS, R.A. 1980. Activity pattern as mechanism of predator avoidance in 2 species of acmaeid limpets. Journal of experimental Marine Biology and Ecology, 48, 151-168.

ZERA, A.J. 1984. Differences in survivorship, development rate and fertility between the longwinged and wingless morphs of the waterstrider Limnoporus canaliculatus. Evolution, 38, 1023-1032. 